ARTICLE

\title{
Integrated redox-active reagents for photoinduced regio- and stereoselective fluorocarboborylation
}

Weigang Zhang ${ }^{1}$, Zhenlei Zou', Wenxuan Zhao ${ }^{1}$, Shuo Lu¹, Zhengguang Wu', Mengjun Huang ${ }^{1}$, Xiaochen Wang ${ }^{1}$, Yi Wang (1) ${ }^{1 凶}$, Yong Liang (10 ${ }^{1 \times}$, Yi Zhu ${ }^{2 凶}$, Youxuan Zheng $\mathbb{B}^{1} \&$ Yi Pan ${ }^{1}$

Vinylboronates and alkylboronates are key components in variegated transformations in all facets of chemical science. The synthesis of vinylboronates and alkylboronates suffers from step-tedious and poor stereoselective procedures. We have developed a regulated radical difunctionalization strategy for the construction of fluorine-containing vinylboronates and alkylboronates with an integrated redox-active reagent IMDN-SO $\mathrm{R}_{\mathrm{F}}$. This bench-stable imidazolium sulfonate cationic salt offers a scalable and operational protocol for the fluoroalkylation-borylation of unsaturated hydrocarbons in a high regio- and stereoselective manner. The products can be further transformed into valuable fluorinated building blocks.

\footnotetext{
${ }^{1}$ State Key Laboratory of Coordination Chemistry, Jiangsu Key Laboratory of Advanced Organic Materials, School of Chemistry and Chemical Engineering Nanjing University, 210023 Nanjing, China. ${ }^{2}$ Key Laboratory of Synthetic and Biological Colloids, Ministry of Education, School of Chemical and Material

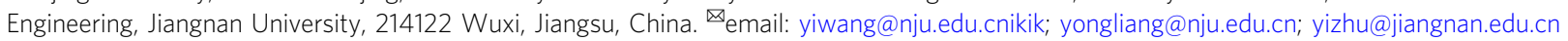


D ifunctionalization of alkenes and alkynes has been widely explored for rapid diversification of double/triple bonds ${ }^{1-6}$. Traditional transition metal-catalyzed difunctionalization methods have been well-developed to control the regioselectivity and stereoselectivity ${ }^{7,8}$. Along these lines, cascade radical addition of unsaturated hydrocarbons in the absence of metallo-intermediate has been realized through careful manipulation of the radical reactivities ${ }^{9-11}$. A single process to achieve radical difunctionalization with extensive functionality tolerance, especially fluorine-containing moieties, is of great value in altering the physical and biological properties of the unsaturated hydrocarbons $s^{4,12-18}$. Studer and co-workers ${ }^{19}$ have reported a radical 1,2-trifluoromethylboration of unactivated alkenes using gaseous $\mathrm{CF}_{3} \mathrm{I}$. Meanwhile, the direct 1,2-fluoroalkylboration of alkynes has also been explored ${ }^{20-22}$. The consequential vicinial vinylboronates, which can be readily transformed to a myriad of fluorine-containing building blocks, have been seldom realized. The only two existing approaches of trifluoromethylated vinylboronates were derived from fluorinated alkynes ${ }^{23}$ and oxiranes $^{24}$. The inaccessibility of those pre-functionalized precursors and operationally tedious procedures prohibited the stepwise fluorination-borylation strategies from practical use (Fig. 1a).

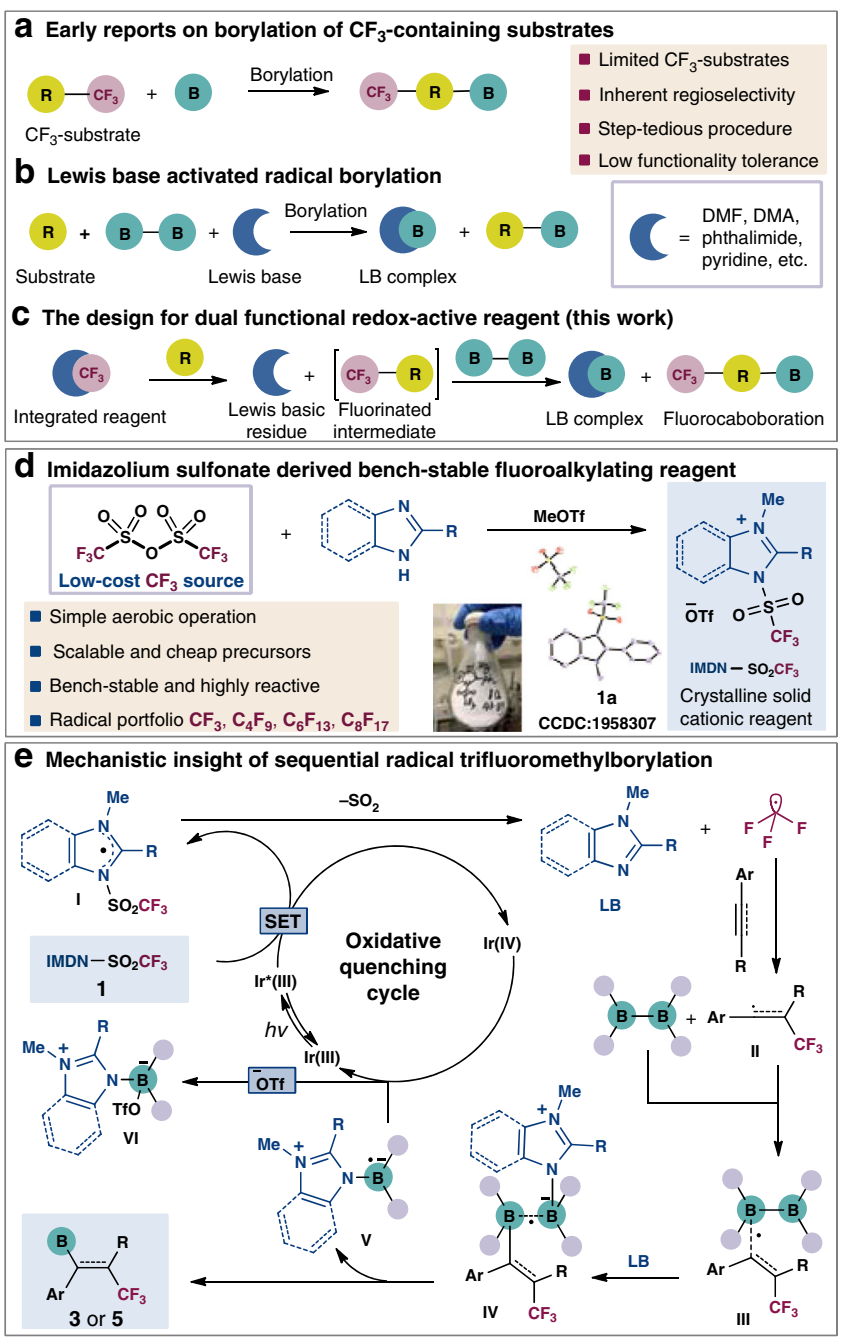

Fig. 1 Origin of the reaction design. a Early reports on borylation of $\mathrm{CF}_{3}$ containing substrates. $\mathbf{b}$ Lewis base-activated radical borylation. $\mathbf{c}$ The design for dual functional redox-active reagent. d Imidazolium sulfonatederived bench-stable fluoroalkylating reagent. e Mechanistic insight of sequential radical trifluoromethylborylation.
Thus, the development of regioselective installation of fluoroalkyl and boronated functionalities to unactivated hydrocarbons in the absence of transition-metal catalysts represents great challenge.

Due to the complexity of radical process incorporating $\mathrm{C}-\mathrm{C}$ and $\mathrm{C}-\mathrm{B}$ bonds formation, several issues need to be addressed, including the reactivities of carbon and boron-centered radicals, the regioselectivity of the radical additions to unsymmetrical alkynes, and stereoselectivity towards $E / Z$ vinylboronates. Typically, a radical borylation process ${ }^{25-32}$ often employs Lewis basic solvents/mediators such as DMAc ${ }^{33,34}, \mathrm{DMF}^{19,35}$, phthalimide ${ }^{36}$, and pyridine $\mathrm{p}^{37,38}$ for the activation of diboron reagents via homolytic cleavage of $\mathrm{B}-\mathrm{B}$ bonds (Fig. 1b). However, the exogenous Lewis base-activated diboron species inevitably deplete $\mathrm{CF}_{3}$ radicals that generated promptly from the trifluromethylating reagents, unable to engage in the desired trifluoromethylborylation sequence (for DFT calculation details, see Supplementary Fig. 18). Inspired by recent radicalinduced difunctionalization strategies 39,40 , we intend to design an integrated reagent that progressively releases $\mathrm{CF}_{3}$ radical for alkene/ alkyne addition, and the endogenous Lewis basic residue subsequently activates the B-B bond for further borylation (Fig. 1c).

Trifluoromethanesulfinate-derived fluorinating reagents have been devised and adopted for direct functionalization of alkenes, alkynes, and arenes ${ }^{41}$. In contrast, the highly hydroscopic and corrosive trifluoromethanesulfonic anhydride $\left(\mathrm{Tf}_{2} \mathrm{O}\right)$ as a trifluoromethyl source is rarely explored. For its strong electrophilic nature, triflic anhydride is commonly used as an alcohol and amine protecting agent ${ }^{42-44}$. Qing and co-workers ${ }^{45}$ have described a triflated pyridine intermediate $\left(\mathrm{Tf}^{-} \mathrm{Py}^{+} . \mathrm{OTf}^{-}\right)$that generated in situ for trifluoromethylated arenes and alkynes. However, the strong electron-withdrawing triflate-derived pyridinium complex is preferably dissociated and unattainable in solid or liquid phase. We speculated that a more basic $N$-heterocycle such as imidazole could harness the highly reactive $\mathrm{Tf}_{2} \mathrm{O}$ to assemble a bench-stable redoxactive reagent. The positive charge of the resulting imidazolium trifluoromethanesulfonate can be delocalized on both nitrogen. Through the cleavage of the stabilized $\mathrm{N}-\mathrm{S}$ bond $(\mathrm{BDE} \approx 70 \mathrm{kcal}$ $\left.\mathrm{mol}^{-1}\right)^{46}$, this cationic complex undergoes SET process to generate $\mathrm{CF}_{3} \mathrm{SO}_{2}$ radical. Meanwhile, as a Lewis base, the imidazole residue can further activate the diboron reagents towards homolytic cleavage of the diboron reagent ${ }^{20,34-39}$. Herein, we have synthesized a dual functional reagent IMDN-SO $\mathrm{SF}_{3} \mathbf{1 a}-\mathbf{1 g}$, a scalable and airstable crystalline salt for a sequential radical fluoroalkylationborylation of unsaturated hydrocarbons (Fig. 1d). First, under the irradiation, $\operatorname{Ir}(\mathrm{III})^{*}$ can reduce the cationic reagent 1 to a neutral radical $I$ and releases $\mathrm{CF}_{3}$ radical, $\mathrm{SO}_{2}$, and imidazole. Then the addition of $\mathrm{CF}_{3}$ to the alkyne regioselectively furnishes vinylic radical II. Subsequent addition of vinyl radical II to $\mathrm{B}_{2} \mathrm{cat}_{2}$ affords a $Z$-vinyl diboron radical III. The control of stereoselectivity is governed by steric repulsion between the trifluoromethyl group and the boronates. The following activation of diboron by the Lewis basic imidazole forms a highly reactive $\mathrm{B}-\mathrm{N}$ heteroleptic intermediate IV, which leads to the carboborylation product 3 and imidazolestabilized boryl radical V. Finally, photo-oxidation of $\mathbf{V}$ followed by coupling with - OTf affords boryl imidazolium salt VI and regenerates Ir(III) (Fig. 1e). These proposed intermediates and selectivities are supported by DFT calculations (see Supplementary Figs. 16-19) This photoinduced cascade radical difunctionalization offers a concise and applicable protocol for constructing highly regio- and stereoselective fluorine-substituted vinylboronates and vicinal fluoroalkyl boronates.

\section{Results}

Reaction optimization. To validate the above hypothesis, we selected phenylacetylene (2a) as pilot substrate to test the trifluoromethylborylation reaction (Table 1). After extensive screening 


\section{Table 1 Optimization of the reaction conditions.}

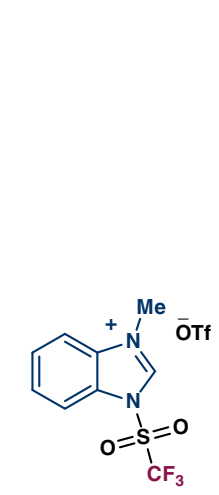

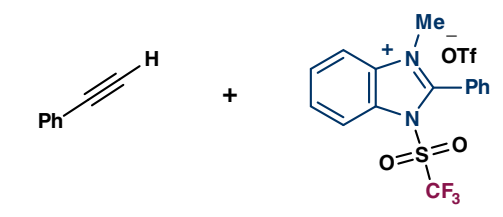

2a

$$
0.2 \mathrm{mmol}
$$

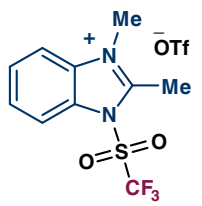

1c, $(-1.212 \mathrm{~V})$

1a, $0.5 \mathrm{mmol}$<smiles></smiles>

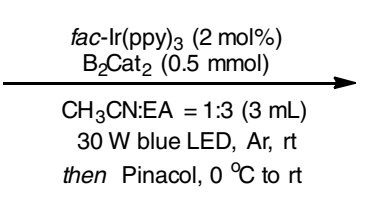

$$
\left(E_{1 / 2}{ }^{\text {red }}=-1.385 \mathrm{~V}\right)
$$

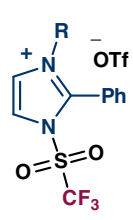

1e, $(-1.273 \mathrm{~V})$

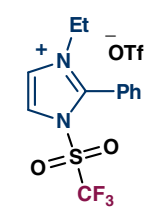

1f, $(-1.349 \mathrm{~V})$

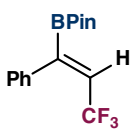

$3 a$

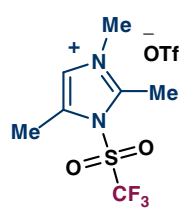<smiles>O=S(=O)(F)n1ccnc1Cc1ccccc1</smiles>

1b, $(-1.273 \mathrm{~V})$

\begin{tabular}{|c|c|c|c|}
\hline Entry & Variation from the conditions & Yield of $3 a^{a}(\%)$ & $Z: E$ of $3 a^{b}$ \\
\hline 1 & None & $82(65)^{c}$ & $>20: 1$ \\
\hline 2 & $\mathbf{1 b}$ instead of $\mathbf{1 a}$ & 67 & $>20: 1$ \\
\hline 3 & $\mathbf{1 c}$ instead of $\mathbf{1 a}$ & 69 & $>20: 1$ \\
\hline 4 & 1d instead of $\mathbf{1 a}$ & 53 & $>20: 1$ \\
\hline 5 & $\mathbf{1 e}$ instead of $\mathbf{1 a}$ & 76 & $>20: 1$ \\
\hline 6 & $\mathbf{1 f}$ instead of $\mathbf{1 a}$ & 60 & $>20: 1$ \\
\hline 7 & $\mathbf{1 g}$ instead of $\mathbf{1 a}$ & 32 & $>20: 1$ \\
\hline 8 & $\mathbf{1 h}$ instead of $\mathbf{1 a}$ & 0 & - \\
\hline 9 & $\mathrm{~B}_{2} \mathrm{pin}_{2}$ instead of $\mathrm{B}_{2} \mathrm{Cat}_{2}$ & 0 & - \\
\hline 10 & $\mathrm{~B}_{2}$ neop $\mathrm{p}_{2}$ instead of $\mathrm{B}_{2} \mathrm{Cat}_{2}$ & 0 & - \\
\hline 11 & 2.0 equiv of pyridine & 58 & $>20: 1$ \\
\hline 12 & 2.0 equiv of 1 -methylimidazole & 47 & $>20: 1$ \\
\hline
\end{tabular}

\section{Variation from the conditions}

$1 \mathrm{~g}(-1.377 \mathrm{~V})$

1h $(-1.808 \mathrm{~V})$

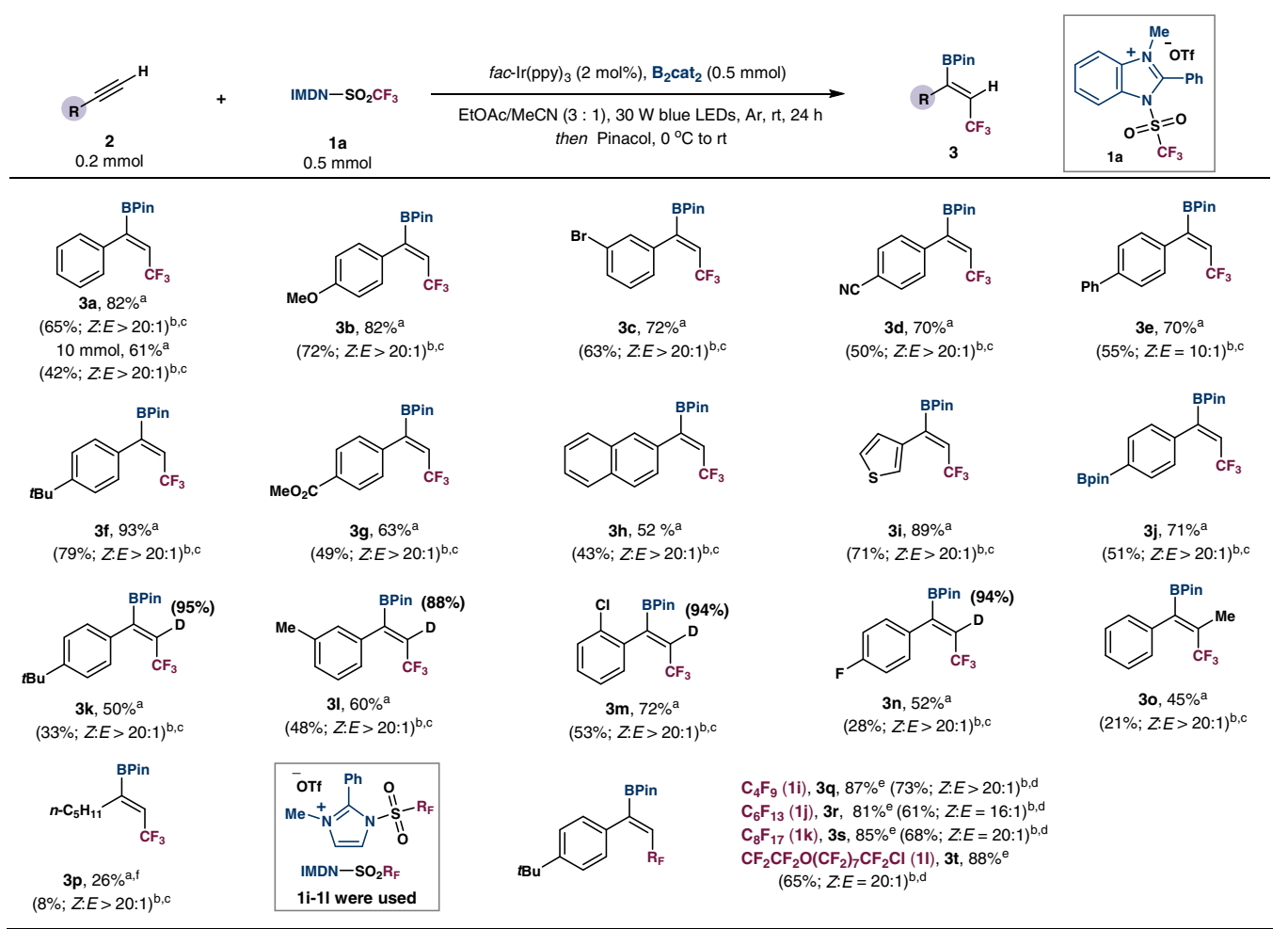

Fig. 2 Substrate scope of the alkynes. aCrude yields determined by ${ }^{19} \mathrm{~F} N \mathrm{NR}$ spectroscopy using benzotrifluoride or trifluoromethoxybenzene as an

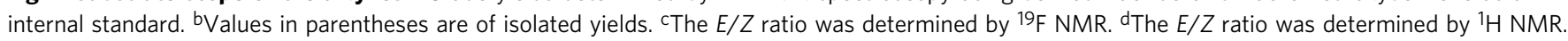
e Crude yields determined by ${ }^{1} \mathrm{H}$ NMR spectroscopy using dibromomethane as an internal standard. ${ }^{\mathfrak{f}} 2.0$ mmol of $\mathbf{2} \mathbf{p}$ was used. 


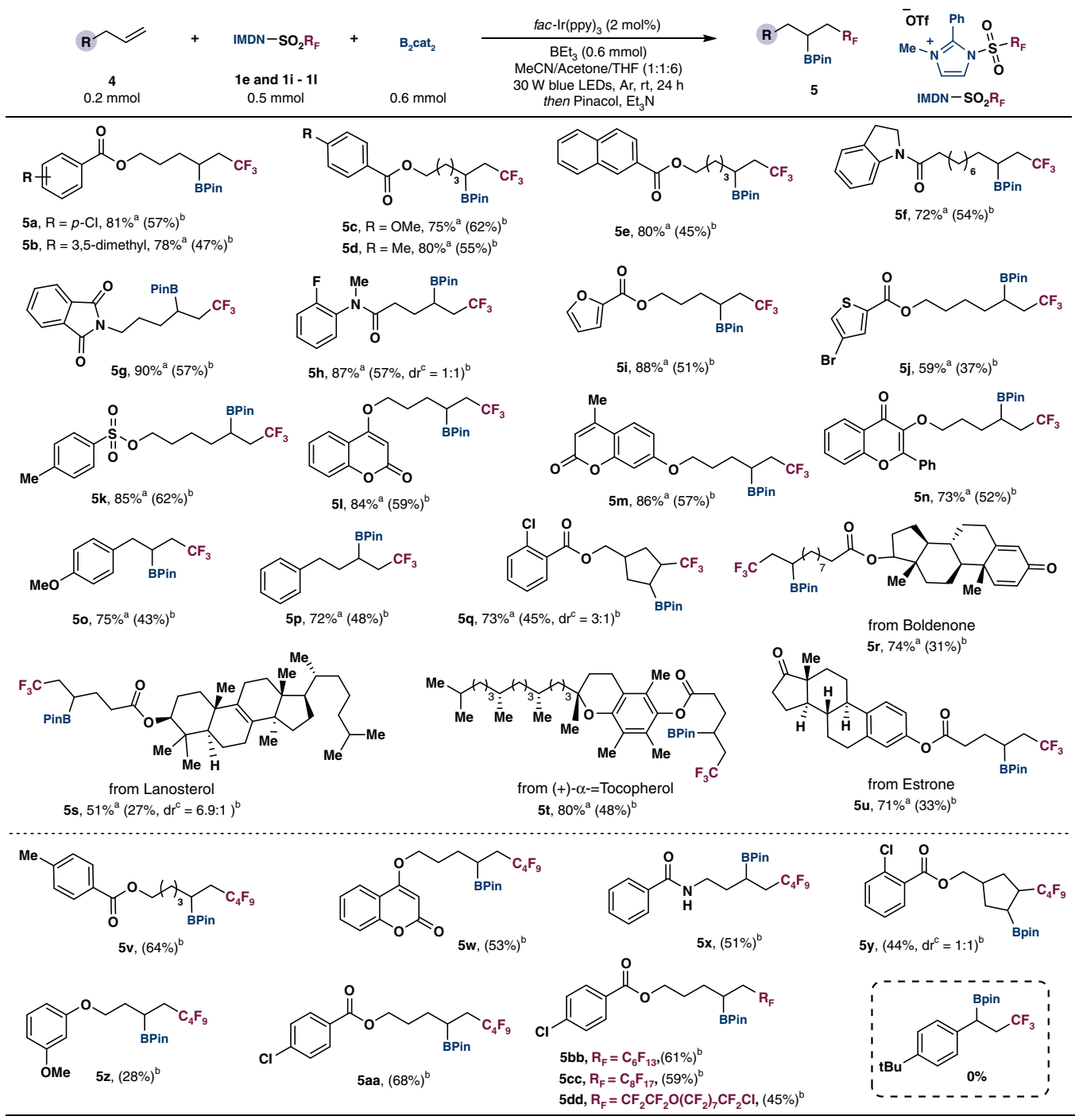

Fig. 3 Substrate scope of the olefins. ${ }^{a}$ Crude yields determined by ${ }^{19} \mathrm{~F}$ NMR. bValues in parentheses are isolated yields. ${ }^{\mathrm{c}}$ The diastereomeric ratio determined by ${ }^{1} \mathrm{H}$ NMR.

of conditions (see Supplementary Tables 1 and 2), we found that when using 2.5 equivalents of $\mathrm{IMDN}_{-} \mathrm{SO}_{2} \mathrm{CF}_{3}$ (1a) $\left(E_{1 / 2}{ }^{\mathrm{red}}=\right.$ $-1.385 \mathrm{~V}$ vs SCE), $2 \mathrm{~mol} \%$ of $f a c-\operatorname{Ir}(\mathrm{ppy})_{3}\left(E_{1 / 2}{ }^{\mathrm{IV} / \mathrm{III}}{ }^{*}=-1.73 \mathrm{~V}\right.$ vs $\mathrm{SCE})^{47}, 2.5$ equivalents of $\mathrm{B}_{2} \mathrm{Cat}_{2}$ in a mixed solvent of $\mathrm{MeCN}$ and EtOAc $(1: 3 \mathrm{v} / \mathrm{v})$ at room temperature under the irradiation of $30 \mathrm{~W}$ blue LEDs, the vinylboronate product $3 \mathrm{a}$ could be obtained in $82 \%$ yield (determined by ${ }^{19} \mathrm{~F}$ NMR) with over 20:1 $\mathrm{Z} / \mathrm{E}$ ratio. Different imidazolium sulfonate reagents $\mathbf{1 b}-\mathbf{1 h}$ were then examined (Table 1). The yield of $\mathbf{3 a}$ descended when the benzoimidazolium reagents $\mathbf{1 b}$ and $\mathbf{1 c}$ were used (entries 2 and 3 ). The counterion was found to be important for this transformation, as evidenced by the low yield (53\%) obtained when using $\mathrm{BF}_{4}^{-}$salt (1d, entry 4). The reaction proceeded with 2 -phenylimidazole reagents $\mathbf{1 e}$ and $\mathbf{1 f}$ in $76 \%$ and $60 \%$ yield, respectively (entries $5-6$ ). The dimethylated reagent $1 \mathrm{~g}$ resulted in a lower conversion (entry 7$)$. The electroneutral reagent $\mathbf{l h}$ failed to produce the desired product under irradiation, which may due to the low reduction potential $\left(E_{1 / 2}{ }^{\text {red }}=-1.808 \mathrm{~V}\right.$ vs SCE) (entry 8$)$. This result validated the precedential presumption that the cationic reagent can serve as a better electron acceptor to furnish $N$-centered neutral radicals ${ }^{48-51}$. Other diboron reagents, such as bis(pinacolato)diboron $\left(\mathrm{B}_{2} \mathrm{pin}_{2}\right)$ and bis(neopentylglycolato)-diboron $\left(\mathrm{B}_{2}\right.$ neop $\left._{2}\right)$, did not provide the corresponding borylated products (entries 9-10). Addition of excess bases such as imidazole and pyridine resulted in much lower yields (entries 11-12).

Substrate scope with respect to the alkynes. Using $2 \mathrm{~mol} \%$ of fac- $\operatorname{Ir}(\mathrm{ppy})_{3}, \mathrm{IMDN}-\mathrm{SO}_{2} \mathrm{CF}_{3}$ (1a) (2.5 equiv), and $\mathrm{B}_{2} \mathrm{cat}_{2}$ (2.5 equiv) at ambient temperature, a range of alkyens underwent fluoroalkylation-borylation with good efficiency. As shown in Fig. 2, the reaction can be performed at a gram scale to give $\mathbf{3} \mathbf{a}$ in $61 \%$ yield and high stereoselectivity. Aromatic alkynes with electro-donating or electro-withdrawing substituents afford the desired products $\mathbf{3 b} \mathbf{b} \mathbf{3} \mathbf{j}$ in good to excellent yields (60-93\%) with high regio- and stereoselectivity $(Z: E>20: 1)$.

Functionalities including halides (3b, 3m, 3n), nitrile (3d), ester (3g), and boronate (3j) are tolerated. Naphthyl- and thienylsubstituted alkynes also readily transformed into the $Z$-products $\mathbf{3 h}$ and $\mathbf{3 i}$ in good yields. The reaction could also be applied to alkynyl deuterium to produce the (Z)-selective deuterated vinylboronates $\mathbf{3 k}-\mathbf{3 n}$ in $52-72 \%$ yields. An attempt of more challenging internal alkyne substrate resulted in the tetrasubstituted olefin in high regio- and stereoselectivity (3o, 45\%). For further investigation of the reaction scope, different fluoroalkylating reagents $\mathbf{1 i}-\mathbf{1 1}$ have been synthesized and applied to the 
standard cabonborylation conditions. Perfluoro-butyl (1i), hexyl (1j), and octanyl (1k) reagents could furnish the corresponding products $\mathbf{3 q}-\mathbf{3 s}$ in good yields (81-87\%). Using a perhalogenated ether-derived sulfonate (11), the vinylboronate $\mathbf{3 t}$ was formed in high yield. To demonstrate the scalability of such radical carboborylation protocol, the reaction was carried out on 10 mmol scale to afford $3 \mathbf{a}$ in $61 \%$ yield with equally high $Z / E$ ratio. Under the standard reaction conditions, alkyl-substituted alkynes could not transform to the desired products. DFT calculations illustrate that the energy barrier of $\mathrm{CF}_{3}$ radical addition to aliphatic alkynes is higher than that to aromatic alkynes. Furthermore, a competing pathway of $\mathrm{CF}_{3}$ radical addition to $\mathrm{B}_{2} \mathrm{Cat}_{2}$ leads to other trifluoromethylated products. Therefore, an excess amount of alkyl alkyne substrate is needed to facilitate the main reaction pathway. By using four equivalents of the alkyne, the borylated product $3 \mathbf{p}$ can be obtained in $26 \%$ yield. For internal aliphatic alkynes, the computed barrier with the $\mathrm{CF}_{3}$ radical is much higher than that for the reaction of $\mathrm{B}_{2} \mathrm{Cat}_{2}$ with the $\mathrm{CF}_{3}$ radical. Therefore, no desired product is obtained using internal aliphatic alkynes as substrate.

Substrate scope with respect to the olefins. The $\alpha$-fluoroalkylated boronates are also useful fluorine-containing synthons for further elaboration. By slight variation of the standard reaction conditions (see Supplementary Tables 3-10), we have extended this carbonborylation protocol to a range of unactivated alkenes (Fig. 3). Using IMDN-SO $\mathrm{C}_{2} \mathrm{CF}_{3}$ (1e), alkenes bearing ester and amide functionalities underwent radical 1,2-carbonboration to afford trifluoromethylated boronates $(\mathbf{5 a}-\mathbf{5 h})$ in good yields. Heteroaryl (5i-5j), sulfonyl (5k), and oxygenated alkyl groups (5l-5n) at various positions of the alkenes were also found effective. Cyclic alkenes could also transform into the desired products $\mathbf{5 q}$ and $\mathbf{5 y}$. Noteworthy, biorelevant molecules, such as boldenone, lanosterol, ( + )- $\alpha$-tocopherol, and estrone-derived terminal alkenes afforded $\beta$-trifluoromethylboronates $(\mathbf{5 r}-\mathbf{5 u})$ in good yields. Additionally, fluoroalkyl radicals including $\cdot \mathrm{C}_{4} \mathrm{~F}_{9}$ (1i), $\cdot \mathrm{C}_{6} \mathrm{~F}_{13}(\mathbf{1 j}), \cdot \mathrm{C}_{8} \mathrm{~F}_{17}(\mathbf{1 k})$, and $\cdot \mathrm{CF}_{2} \mathrm{CF}_{2} \mathrm{O}\left(\mathrm{CF}_{2}\right)_{7} \mathrm{CF}_{2} \mathrm{Cl}(\mathbf{1})$ were successfully stitched to unactivated olefins to afford fluoroalkylborylated products in moderate yields $(\mathbf{5} \mathbf{v}-\mathbf{5 d d})$. The reaction with styrene failed to afford the desired product due to inert reactivity of benzylic radical.

Synthetic applications. The synthetic utility of the method was demonstrated in a number of transformations of the highly functionalized alkylboronates and alkenylboronates ${ }^{20,52,53}$ (Fig. 4). Oxidation of $\beta-\mathrm{CF}_{3}$ boronate $\mathbf{5 a}$ afforded hydroxylated product $\mathbf{6}$ in $62 \%$ yield. Silver-catalyzed radical deboronofluorination of $\mathbf{5 a}$ in aqueous solution provided the alkyl fluoride 7 in $76 \%$ yield. Vinylation, oxidative coupling, and homologation of $5 p$ afforded functionalized products 8-10 in good yields. Halogenation of vinylboronic ester 3a resulted in the formation of $\beta-\mathrm{CF}_{3}$-vinyl bromide 11(53\%). Palladium-catalyzed Suzuki-Miyaura crosscoupling of $\mathbf{3 a}$ with (hetero)aryl iodides afforded the corresponding trisubstituted alkenes $\mathbf{1 2}(90 \%)$ and $\mathbf{1 5}(88 \%)$. Olefination and alkynylation using vinyl bromide or alkynyl bromide also proceeded smoothly to generate $\mathbf{1 3}$ and $\mathbf{1 4}$ in $73 \%$ and $96 \%$ yields, respectively. The coupling of $\mathbf{3 a}$ with bioactive estrone-derived triflate produced the corresponding product $\mathbf{1 6}$ with high stereoselectivity.

\section{Discussion}

In summary, we have described an air-stable redox-active reagent IMDN-SO $\mathrm{S}_{\mathrm{F}} \mathbf{1}$ with high reactivity and scalability. A key design feature of this dual functional imidazolium sulfonate reagent is the cationic nature that favors the progressive formation of

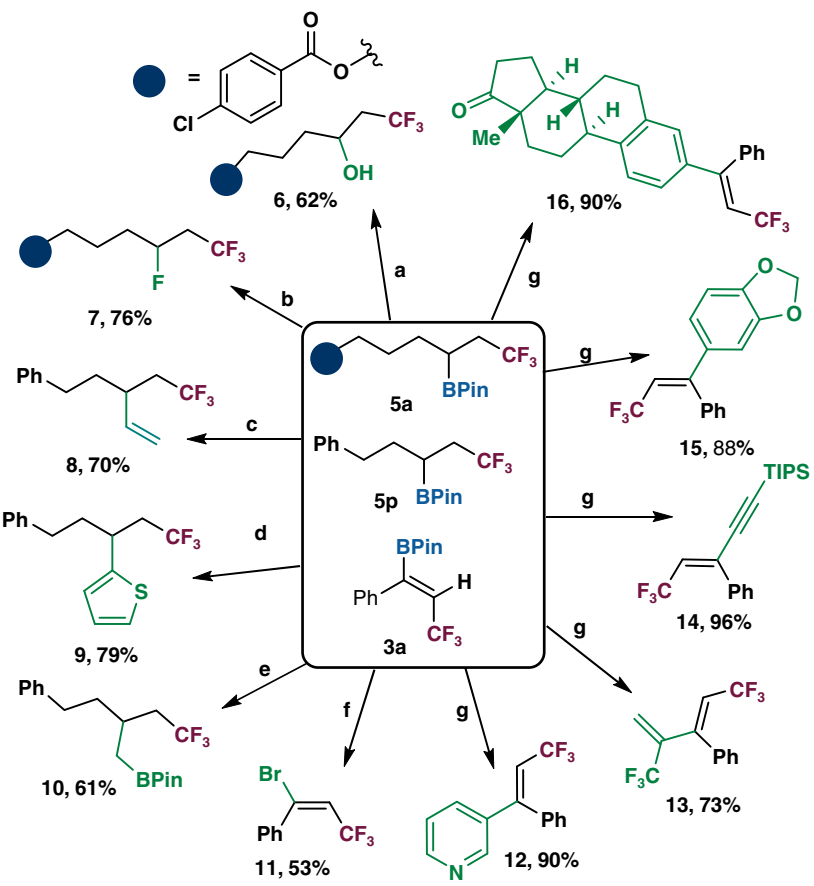

Fig. 4 Further transformations. ${ }^{a} \mathrm{H}_{2} \mathrm{O}_{2}(30 \%), \mathrm{NaOH}(3 \mathrm{M}), \mathrm{THF}, \mathrm{O}^{\circ} \mathrm{C}$ to rt. bSelectfluor, $\mathrm{AgNO}_{3}, \mathrm{TFA}, \mathrm{H}_{3} \mathrm{PO}_{4}, \mathrm{DCM} / \mathrm{H}_{2} \mathrm{O}, 50^{\circ} \mathrm{C}$. CVinylmagnesium bromide, $\mathrm{I}_{2}, \mathrm{THF},-78^{\circ} \mathrm{C}$ to $0^{\circ} \mathrm{C}$. ${ }^{\mathrm{d}} \mathrm{n}$-BuLi, NBS, thiophene, $\mathrm{THF},-78^{\circ} \mathrm{C}$.

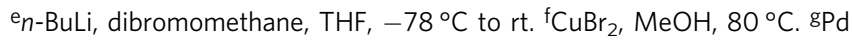
$\left(\mathrm{PPh}_{3}\right)_{4}(5 \mathrm{~mol} \%), \mathrm{Cs}_{2} \mathrm{CO}_{3}$, toluene, $\mathrm{H}_{2} \mathrm{O}, 80^{\circ} \mathrm{C}$.

fluoroalkyl radicals by SET reduction under photocatalytic conditions. Meanwhile, the in situ-generated Lewis basic imidazole residue promotes the B-B bond cleavage. The integrated reagent is applicable to regulate the reaction sequence of carbon and boron-centered radicals to access various fluorine-bearing vinylboronates and alkylboronates with high stereo- and regioselectivities. Further study of this reagent is underway in our laboratory.

\section{Methods}

General procedure for the synthesis of imidazolium salts 1. To a one-necked $1000 \mathrm{~mL}$ flask equipped with a magnetic stirrer, the corresponding imidazole $(100 \mathrm{mmol}), \mathrm{Et}_{3} \mathrm{~N}(150 \mathrm{mmol})$, and $600 \mathrm{~mL}$ DCM were added. The flask was then cooled in an ice bath, and $130 \mathrm{mmol}(36.8 \mathrm{~g})\left(\mathrm{CF}_{3} \mathrm{SO}_{2}\right)_{2} \mathrm{O}$ was bubbled into the flask slowly. The mixture was stirred at room temperature for $2 \mathrm{~h}$ and evaporated in vacuo, quenched with water, and extracted with ethyl acetate $(300 \mathrm{~mL} \times 3)$. The combined organic layers were dried over $\mathrm{Na}_{2} \mathrm{SO}_{4}$, filtered, and concentrated. The product was purified by flash column chromatography on silica gel with $n$-pentane/ ethyl acetate as eluent to give the imidazolyl sulfonamide. Under argon, to a solution of the imidazolyl sulfonamide in dried DCM $(400 \mathrm{~mL})$ was added dropwise MeOTf (or $\left.\mathrm{Me}_{3} \mathrm{OBF}_{4}\right)(130 \mathrm{mmol})$ at $0{ }^{\circ} \mathrm{C}$. Then, the mixture was stirred at room temperature for $12 \mathrm{~h}$. (If EtOTf is used, the reaction is refluxed for $24 \mathrm{~h}$.) After that, the mixture was concentrated under rotary evaporation to give a white solid (or a viscous liquid) crude product, to which $\mathrm{Et}_{2} \mathrm{O}(300 \mathrm{~mL})$ was added. With vigorous stirring, a solid precipitate was formed and washed with $\mathrm{Et}_{2} \mathrm{O}(200 \mathrm{~mL} \times$ 3 ) and dried in vacuo to yield the imidazolium salt $\mathbf{1}$ as a white solid.

General procedure for the synthesis of vinylboronates 3. Under argon, to a solution of 1 ( $0.50 \mathrm{mmol}, 2.5$ equiv), $\mathrm{B}_{2} \mathrm{Cat}_{2}\left(0.5 \mathrm{mmol}, 2.5\right.$ equiv) and $f a c$ - $\operatorname{Ir}(\mathrm{ppy})_{3}$ $(2 \mathrm{~mol} \%)$ in MeCN:EtOAc (1:3) $(3 \mathrm{~mL})$ was added corresponding alkynes 2 $(0.2 \mathrm{mmol})$ at room temperature. After that, the tube was exposed to $30 \mathrm{~W}$ blue LEDs at room temperature about $30 \mathrm{~h}$ until the reaction was completed as monitored by TLC or GC-MS analysis. A solution of pinacol ( $236 \mathrm{mg}, 2 \mathrm{mmol})$ in $\mathrm{MeCN}$ $(1.0 \mathrm{~mL})$ was added dropwise to the mixture at $0{ }^{\circ} \mathrm{C}$. After $1 \mathrm{~h}$, saturated ammonium chloride solution $(15 \mathrm{~mL})$ was added and the aqueous layer was extracted with hexane $(3 \times 15 \mathrm{~mL})$. The combined organic layers were dried over $\mathrm{Na}_{2} \mathrm{SO}_{4}$, filtered, and concentrated. The product was purified by flash column chromatography on silica gel with $n$-pentane/ethyl acetate as eluent to give the vinylboronates 3 . 
General procedure for the synthesis of alkylboronates $\mathbf{5}$. Under argon, to a solution of $1\left(0.50 \mathrm{mmol}, 2.5\right.$ equiv), $\mathrm{B}_{2} \mathrm{Cat}_{2}\left(0.6 \mathrm{mmol}, 3.0\right.$ equiv) and $\mathrm{fac}-\operatorname{Ir}(\mathrm{ppy})_{3}$ $(2 \mathrm{~mol} \%)$ in 1:1 MeCN/acetone $(0.2 \mathrm{~mL})$ was added $\mathrm{Et}_{3} \mathrm{~B}(0.6 \mathrm{mmol}, 3.0$ equiv, $1 \mathrm{~mol} / \mathrm{L}$ in THF) and corresponding alkenes $4(0.2 \mathrm{mmol})$ at room temperature. After that, the tube was exposed to $30 \mathrm{~W}$ blue LEDs at room temperature for $30 \mathrm{~h}$ until the reaction was completed as monitored by TLC or GC-MS analysis. A solution of pinacol $(142 \mathrm{mg}, 1.2 \mathrm{mmol})$ in $\mathrm{Et}_{3} \mathrm{~N}(1.1 \mathrm{~mL})$ was added to the mixture. After $1 \mathrm{~h}$, the reaction mixture was evaporated in vacuo. The product was purified by flash column chromatography on silica gel with $n$-pentane/ethyl acetate as eluent to give the alkylboronates $\mathbf{5}$.

\section{Data availability}

The authors declare that the main data supporting the findings of this study, including experimental procedures and compound characterization, are available within the article and its Supplementary Information files. X-ray structural data of compound 1a are available free of charge from the Cambridge Crystallographic Data Center under the deposition number CCDC 1958307. These data can be obtained free of charge from The Cambridge Crystallographic Data Center via www.ccdc.cam.ac. uk/data_request/cif.

Received: 1 February 2020; Accepted: 30 April 2020;

Published online: 22 May 2020

\section{References}

1. Song, H.-X., Han, Q.-Y., Zhao, C.-L. \& Zhang, C.-P. Fluoroalkylation reactions in aqueous media: a review. Green Chem. 20, 1662-1731 (2018).

2. Hoffmann, R. W. Markovnikov free radical addition reactions, a sleeping beauty kissed to life. Chem. Soc. Rev. 45, 577-583 (2016).

3. Greenhalgh, M. D., Jones, A. S. \& Thomas, S. P. Iron-catalysed hydrofunctionalisation of alkenes and alkynes. ChemCatChem 7, 190-222 (2015).

4. Alonso, C., Martinez de Marigorta, E., Rubiales, G. \& Palacios, F. Carbon trifluoromethylation reactions of hydrocarbon derivatives and heteroarenes. Chem. Rev. 115, 1847-1935 (2015)

5. Merino, E. \& Nevado, C. Addition of $\mathrm{CF}_{3}$ across unsaturated moieties: a powerful functionalization tool. Chem. Soc. Rev. 43, 6598-6608 (2014).

6. Zeng, X. Recent advances in catalytic sequential reactions involving hydroelement addition to carbon-carbon multiple bonds. Chem. Rev. 113, 6864-6900 (2013).

7. Li, Y., Wu, D., Cheng, H.-G. \& Yin, G. Difunctionalization of alkenes involving metal migration. Angew. Chem. Int. Ed. 59, 2-16 (2020).

8. Yin, G., Mu, X. \& Liu, G. Palladium (II)-catalyzed oxidative difunctionalization of alkenes: bond forming at a high-valent palladium center. Acc. Chem. Res. 49, 2413-2423 (2016).

9. Sivaguru, P., Wang, Z., Zanoni, G. \& Bi, X. Cleavage of carbon-carbon bonds by radical reactions. Chem. Soc. Rev. 48, 2615-2656 (2019).

10. Ravelli, D., Protti, S. \& Fagnoni, M. Carbon-carbon bond forming reactions via photogenerated intermediates. Chem. Rev. 116, 9850-9913 (2016).

11. Wille, U. Radical cascades initiated by intermolecular radical addition to alkynes and related triple bond systems. Chem. Rev. 113, 813-853 (2013).

12. Tomashenko, O. A. \& Grushin, V. V. Aromatic trifluoromethylation with metal complexes. Chem. Rev. 111, 4475-4521 (2011).

13. Nie, J., Guo, H.-C., Cahard, D. \& Ma, J.-A. Asymmetric construction of stereogenic carbon centers featuring a trifluoromethyl group from prochiral trifluoromethylated substrates. Chem. Rev. 111, 455-529 (2011).

14. Zhang, W. et al. Leaving group assisted strategy for photoinduced fluoroalkylations using $N$-hydroxybenzimidoyl chloride esters. Angew. Chem. Int. Ed. 58, 624-627 (2019).

15. Daniel, M. et al. Fluorinated sulfilimino iminiums: efficient and versatile sources of perfluoroalkyl radicals under photoredox catalysis. Angew. Chem. Int. Ed. 56, 3997-4001 (2017).

16. Wang, F., Wang, D., Mu, X., Chen, P. \& Liu, G. Copper-catalyzed intermolecular trifluoromethylarylation of alkenes: mutual activation of arylboronic acid and $\mathrm{CF}_{3}{ }^{+}$reagent. J. Am. Chem. Soc. 136, 10202-10205 (2014).

17. Wang, F., Qi, X., Liang, Z., Chen, P. \& Liu, G. Copper-catalyzed intermolecular trifluoromethylazidation of alkenes: convenient access to $\mathrm{CF}_{3}$ containing alkyl azides. Angew. Chem. Int. Ed. 53, 1881-1886 (2014).

18. Liang, Z., Wang, F., Chen, P. \& Liu, G. Copper-catalyzed intermolecular trifluoromethylthiocyanation of alkenes: convenient access to $\mathrm{CF}_{3}$-containing alkyl thiocyanates. Org. Lett. 17, 2438-2441 (2015).

19. Cheng, Y., Muck-Lichtenfeld, C. \& Studer, A. Transition metal-free 1, 2 carboboration of unactivated alkenes. J. Am. Chem. Soc. 140, 6221-6225 (2018).
20. Guo, W.-H., Zhao, H.-Y., Luo, Z.-J., Zhang, S. \& Zhang, X. Fluoroalkylationborylation of alkynes: an efficient method to obtain $(Z)$-tri- and tetrasubstituted fluoroalkylated alkenylboronates. ACS Catal. 9, 38-43 (2019).

21. Domanski, S., Gatlik, B. \& Chaładaj, W. Pd-catalyzed boroperfluoroalkylation of alkynes opens a route to one-pot reductive carboperfluoroalkylation of alkynes with perfluoroalkyl and aryl iodides. Org. Lett. 21, 5021-5025 (2019).

22. Wang, S. et al. Palladium-catalyzed anti-selective fluoroalkylboration of internal and terminal alkynes. Org. Lett. 20, 5631-5635 (2018).

23. Liu, X., Shimizu, M. \& Hiyama, T. A facile stereocontrolled approach to $\mathrm{CF}_{3}$ substituted triarylethenes: synthesis of panomifene. Angew. Chem. Int. Ed. 43, 879-882 (2004).

24. Konno, T., Chae, J., Tanaka, T., Ishihara, T. \& Yamanaka, H. A sequential highly stereoselective hydroboration and Suzuki-Miyaura cross-coupling reaction of fluoroalkylated internal acetylenes: a practical one-pot synthesis of fluoroalkylated trisubstituted alkenes. Chem. Commun. 40, 690-691 (2004).

25. Wu, J., Bar, R. M., Guo, L., Noble, A. \& Aggarwal, V. K. Photoinduced deoxygenative borylations of aliphatic alcohols. Angew. Chem. Int. Ed. 58, 18830-18834 (2019)

26. Friese, F. W. \& Studer, A. Deoxygenative borylation of secondary and tertiary alcohols. Angew. Chem. Int. Ed. 58, 9561-9564 (2019).

27. Yan, G., Huang, D. \& Wu, X. Recent advances in C-B bond formation through a free radical pathway. Adv. Synth. Catal. 360, 1040-1053 (2018).

28. Xu, L. Decarboxylative borylation: new avenues for the preparation of organoboron compounds. Eur. J. Org. Chem. 2018, 3884-3890 (2018).

29. Wang, J. et al. Cu-catalyzed decarboxylative borylation. ACS Catal. 8, 9537-9542 (2018)

30. Li, C. et al. Decarboxylative borylation. Science 356, 1045-1052 (2017).

31. Yang, C. T. et al. Alkylboronic esters from copper-catalyzed borylation of primary and secondary alkyl halides and pseudohalides. Angew. Chem. Int. Ed. 51, 528-532 (2012)

32. Dudnik, A. S. \& Fu, G. C. Nickel-catalyzed coupling reactions of alkyl electrophiles, including unactivated tertiary halides, to generate carbon-boron bonds. J. Am. Chem. Soc. 134, 10693-10697 (2012).

33. Wu, J., He, L., Noble, A. \& Aggarwal, V. K. Photoinduced deaminative borylation of alkylamines. J. Am. Chem. Soc. 140, 10700-10704 (2018).

34. Sandfort, F., Strieth-Kalthoff, F., Klauck, F. J. R., James, M. J. \& Glorius, F. Deaminative borylation of aliphatic amines enabled by visible light excitation of an electron donor-acceptor complex. Chem. Eur. J. 24, 17210-17214 (2018).

35. Cheng, Y., Muck-Lichtenfeld, C. \& Studer, A. Metal-free radical borylation of alkyl and aryl iodides. Angew. Chem. Int. Ed. 57, 16832-16836 (2018).

36. Fawcett, A. et al. Photoinduced decarboxylative borylation of carboxylic acids Science 357, 283-286 (2017)

37. Hu, J., Wang, G., Li, S. \& Shi, Z. Selective C-N borylation of alkyl amines promoted by Lewis base. Angew. Chem. Int. Ed. 57, 15227-15231 (2018).

38. Candish, L., Teders, M. \& Glorius, F. Transition-metal-free, visible-lightenabled decarboxylative borylation of aryl $N$-hydroxyphthalimide esters. $J$. Am. Chem. Soc. 139, 7440-7443 (2017).

39. Monos, T. M., McAtee, R. C. \& Stephenson, C. R. J. Arylsulfonylacetamides as bifunctional reagents for alkene aminoarylation. Science 361, 1369-1373 (2018).

40. Lan, X., Wang, N. \& Xing, Y. Recent advances in radical difunctionalization of simple alkenes. Eur. J. Org. Chem. 2017, 5821-5851 (2017).

41. Ni, C., Hu, M. \& Hu, J. Good partnership between sulfur and fluorine: sulfurbased fluorination and fluoroalkylation reagents for organic synthesis. Chem. Rev. 115, 765-825 (2015).

42. Xu, X. H., Matsuzaki, K. \& Shibata, N. Synthetic methods for compounds having $\mathrm{CF}_{3}-\mathrm{S}$ units on carbon by trifluoromethylation, trifluoromethylthiolation, triflylation, and related reactions. Chem. Rev. 115, 731-764 (2015).

43. Shainyan, B. A. \& Tolstikova, L. L. Trifluoromethanesulfonamides and related compounds. Chem. Rev. 113, 699-733 (2013).

44. Baraznenok, I. L., Nenajdenko, V. G. \& Balenkova, E. S. Chemical transformations induced by triflic anhydride. Tetrahedron 56, 3077-3119 (2000).

45. Ouyang, Y., Xu, X. H. \& Qing, F. L. Trifluoromethanesulfonic anhydride as a low-cost and versatile trifluoromethylation reagent. Angew. Chem. Int. Ed. 57, 6926-6929 (2018)

46. Kraka, E., Setiawan, D. \& Cremer, D. Re-evaluation of the bond length-bond strength rule: the stronger bond is not always the shorter bond. J. Comput. Chem. 37, 130-142 (2016).

47. Kelly, C. B. et al. Preparation of visible-light-activated metal complexes and their use in photoredox/nickel dual catalysis. Nat. Protoc. 12, 472-492 (2017)

48. Lee, J. W., Zheng, W., Morales-Rivera, C. A., Liu, P. \& Ngai, M.-Y. Catalytic radical difluoromethoxylation of arenes and heteroarenes. Chem. Sci. 10, 3217-3222 (2019)

49. Bao, X., Wang, Q. \& Zhu, J. Dual photoredox/copper catalysis for the remote $\mathrm{C}\left(\mathrm{sp}^{3}\right)$ - $\mathrm{H}$ functionalization of alcohols and alkyl halides by $\mathrm{N}$ alkoxypyridinium salts. Angew. Chem. Int. Ed. 58, 2139-2143 (2019). 
50. Zheng, W., Lee, J. W., Morales-Rivera, C. A., Liu, P. \& Ngai, M. Y. Redox-active reagents for photocatalytic generation of the $\mathrm{OCF}_{3}$ radical and (hetero)aryl C-H trifluoromethoxylation. Angew. Chem. Int. Ed. 57, 13795-13799 (2018).

51. Kim, I. et al. Visible-light-induced pyridylation of remote $\mathrm{C}\left(\mathrm{sp}^{3}\right)-\mathrm{H}$ bonds by radical translocation of $\mathrm{N}$-alkoxypyridinium salts. Angew. Chem. Int. Ed. 57, 15517-15522 (2018).

52. $\mathrm{Wu}$, N.-Y., Xu, X.-H. \& Qing, F.-L. Copper-catalyzed regioselective borylfluoromethylation of alkenes. ACS Catal. 9, 5726-5731 (2019).

53. Su, W. et al. Ligand-controlled regiodivergent copper-catalyzed alkylboration of unactivated terminal alkynes. ACS Catal. 6, 6417-6421 (2016).

\section{Acknowledgements}

Financial support from the National Natural Science Foundation of China (No. 21772085 and No. 21971107) and the Natural Science Foundation of Jiangsu Province (BK20170631) is gratefully acknowledged. The numerical calculations in this paper have been done on the computing facilities in the High Performance Computing Centers of Nanjing University and Collaborative Innovation Center of Advanced Microstructures and Collaborative Innovation Center of Solid-State Lighting and Energy-Saving Electronics.

\section{Author contributions}

Y.W. designed and guided this project. W. Zhang, Z.Z., Z.W., and M.H. are responsible for the plan and implementation of the experimental work. Y.L., W. Zhao, and S.L. are responsible for the calculation studies. Y.W., X.W., Y.L., Y. Zhu, Y. Zheng, and Y.P. cowrote the manuscript, analyzed the data, discussed the results, and commented on the manuscript.

\section{Competing interests}

The authors declare no competing interests.

\section{Additional information}

Supplementary information is available for this paper at https://doi.org/10.1038/s41467 020-16477-1.

Correspondence and requests for materials should be addressed to Y.W., Y.L. or Y.Z.

Peer review information Nature Communications thanks the anonymous reviewer(s) for their contribution to the peer review of this work. Peer reviewer reports are available.

Reprints and permission information is available at http://www.nature.com/reprints

Publisher's note Springer Nature remains neutral with regard to jurisdictional claims in published maps and institutional affiliations.

(c) (i) Open Access This article is licensed under a Creative Commons Attribution 4.0 International License, which permits use, sharing, adaptation, distribution and reproduction in any medium or format, as long as you give appropriate credit to the original author(s) and the source, provide a link to the Creative Commons license, and indicate if changes were made. The images or other third party material in this article are included in the article's Creative Commons license, unless indicated otherwise in a credit line to the material. If material is not included in the article's Creative Commons license and your intended use is not permitted by statutory regulation or exceeds the permitted use, you will need to obtain permission directly from the copyright holder. To view a copy of this license, visit http://creativecommons.org/ licenses/by/4.0\%

(c) The Author(s) 2020 